\title{
Evolution in fixed-time: from synchronization of ovulation to improved fertility
}

\author{
Mario Binelli ${ }^{1}$, Roberto Sartori ${ }^{2}$, José Luiz Moraes Vasconcelos ${ }^{3}$, \\ Pedro Leopoldo Jerônimo Monteiro Jr. ${ }^{2}$, Marcos Henrique Colombo Pereira ${ }^{3}$ \\ and Roney S. Ramos ${ }^{1}$ \\ ${ }^{1}$ Department of Animal Reproduction, School of Veterinary Medicine and Animal Science, University \\ of São Paulo (USP), Pirassununga, SP 13635-900, Brazil; ' ${ }^{2}$ Department of Animal Science, ESALQ, \\ University of São Paulo (USP), Piracicaba, SP, Brazil 13418-900; ${ }^{3}$ Department of Animal Production, \\ School of Veterinary Medicine and Animal Science, São Paulo State University (UNESP), Botucatu, SP \\ 18168-000, Brazil.
}

\begin{abstract}
Summary
Synchronization of ovulation and subsequent timed artificial insemination became a popular practice in modern, large scale, dairy and beef commercial operations. Popularity was because it became a serious option to eliminate a laborious and low efficiency activity in the industry: checking cows for heat. Synchronization protocols involve the sequential administration of reproductive hormones to manipulate the estrous cycle to provide a fertile oocyte for insemination at a predictable moment. In the last 20 years, great effort was put forth in protocol development and adjustment; current rates of synchronous ovulations are $80-90 \%$. Moreover, fertility to current protocols is similar to that obtained in cows inseminated after heat detection. The present wave of protocol development proposes to face the challenge of further improving pregnancy success of current protocols. The guiding principle is that, due to the intense metabolism associated with copious milk production, steroid hormone concentrations are insufficient for adequate reproductive function. Thus, new protocols have incorporated strategies to adjust the endocrine milieu and consequently support specific portions of the synchronization process. This paper discusses the positive fertility impact of protocol design that incorporated the following concepts: controlling P4 concentrations during follicle growth to increase oocyte quality; reducing circulating $\mathrm{P} 4$ prior to $\mathrm{Al}$ to increase proportion of cows pregnant; providing estrogen priming during proestrus to benefit conception and reduce embryo mortality; and optimizing progesterone priming during early diestrus to enhance conceptus survival. It is expected that adoption of these concepts will lead to a continuous increase in fertility of lactating dairy cows.
\end{abstract}




\section{Introduction}

The scientific community owes a lot of respect to the Estrus Synchronization Pioneers. They provided the entire biological basis so that in the 1990's, simple and successful protocols for the synchronization of ovulation and fixed-time artificial insemination (FTAI) were devised and applied massively to bovine production commercial operations around the world (review: Wiltbank \& Pursley 2014). Protocols entail strategic administration of reproductive hormones in a sequential manner with a single objective: the ovulation of a follicle carrying a healthy oocyte at a moment compatible with fertilization by Al. Thus, the focus is to program ovarian events to occur in a timely fashion to ultimately provide an oocyte for fertilization and subsequently optimal embryo development leading to a pregnancy. Ovarian events that need effective programming and respective hormones (or pharmaceutical analogs) commonly used for programming are: recruiting a follicular wave $[\mathrm{GnRH}$, estrogens (estradiol $17 \beta$ and its esters; E2)/progestagens including progesterone (P4)], temporary blocking of ovulations (P4), efficient regression of corpora lutea $(\mathrm{CL})$ to decrease $\mathrm{P} 4$ concentrations prior to ovulation [prostaglandin F2 $\alpha$ (PGF)], and ovulation [GnRH, E2]. There are two basic categories of protocols. The OvSynch-type protocols, utilize GnRH to synchronize the follicular wave by ovulation of a dominant follicle at the start of the protocol, and to synchronize ovulation at the end of the protocol allowing FTAI. The E2/P4-based protocols start using E2 products in the presence of $\mathrm{P} 4$ to induce atresia of follicles and synchronize emergence of a new follicular wave. At the end of E2/P4-based protocol, another E2 treatment in the absence of P4 is used to synchronize ovulation and allow FTAI. Choice of protocols and drugs depend on technical and economic decisions taken by farm personnel and, more importantly, according to regulatory constraints on drug usage, specific to different countries.

Fertility success to protocols is measured in terms of proportion of cows pregnant or pregnancy rate (PR). Mathematical formulation for PR is equal to proportion of cows serviced $x$ proportion of cows pregnant that were serviced. Proportion of cows serviced $=$ the number of cows receiving $\mathrm{Al} \div$ number of cows eligible to receive $\mathrm{Al}$, and proportion of cows pregnant $=$ the number of cows pregnant $\div$ number of cows receiving $\mathrm{AI}(\mathrm{P} / \mathrm{Al})$. Researchers rationalized that maximization of PR of the herd would result from maximizing both proportion of cows serviced and P/AI. Before FTAI, limitations to proportion of cows serviced were a high proportion of anovular cows, which did not show heat, and inefficient detection of cows in heat. Thus, seminal contributions of FTAI to the animal industry were to both induce cyclicity in anovular cows and eliminate the need for detection of estrus, because all cows eligible to Al were in fact inseminated.

Next, it became important to understand the influence of FTAI protocols on P/AI. Santos et al. (2009) compared P/AI between cows inseminated to detected heat and treated to receive FTAI. P/AI were similar between groups. More recently, Nascimento et al. (2013a) compiled experimental results involving 48 herds and 83,771 cows. The P/AI of groups of animals treated with hormonal protocols and submitted to FTAI were compared to control groups, in which cows were $\mathrm{Al}$ at detected estrus. Again, overall first service P/AI was $35.4 \%$ for the detection of estrus group and $36.1 \%$ for the FTAI group. Interpretation is that classical protocols achieve $\mathrm{P} / \mathrm{Al}$ comparable to the cow's natural fertility potential. Next, question became why fertility is low and can it be increased. We propose that the next step in protocol development is to devise treatments aiming to increase P/AI of FTAI cows relative to cows bred to a natural heat. Current protocols must do more than mimic endocrine events to provide an adequately timed oocyte for Al. Modern protocols must incorporate the understanding that the high yield dairy cow has an altered reproductive hormone milieu that affects fertility directly and that is a target for therapeutic interventions. Here, we will discuss concepts that have been applied to novel 
protocols for the lactating dairy cow. Specifically, the following topics will be discussed: (1) controlling P4 concentrations during follicle growth to increase oocyte quality and to effectively reduce circulating $\mathrm{P} 4$ associated with $\mathrm{CL}$ regression prior to $\mathrm{Al}$; (2) providing estrogen priming during proestrus to benefit conception and reduce embryo mortality; and (3) optimizing progesterone priming during early diestrus to enhance conceptus survival.

\section{The abnormal reproductive endocrine profile of the modern dairy cow is associated with reduced fertility}

The design of fixed-time protocols to synchronize ovulation requires an understanding and characterization of the reproductive physiology of the modern dairy cow, and how management and nutrition affect it. There is a high positive correlation between dry matter feed intake and milk production. The high feed intake can alter ovarian physiology and hormone concentrations. High-producing cows in lactation have larger size follicles; however, E2 concentrations in blood are lower compared to heifers and non-lactating cows (De La Sota et al. 1993, Sartori et al. 2002a, Wolfenson et al. 2004). It is well known that the size of the ovulatory follicle has a high positive correlation with size of CL (Vasconcelos et al. 2001, Sartori et al. 2002a) and consequently this may be reflected in circulating P4 concentrations (Moreira et al. 2000). However, despite lactating dairy cows having larger $\mathrm{CL}$, their circulating P4 concentrations are also lower than those of heifers and non-lactating cows (Sartori et al. 2002a, Sartori et al. 2004, Wolfenson et al. 2004). Lower circulating P4 has also been related to the increased incidence of follicle co-dominance and double ovulation observed in lactating cows, but not in heifers. Increasing blood P4 by manipulating the estrous cycle with exogenous hormonal treatments has reduced the incidence of multiple ovulations in dairy cows (Wiltbank et al. 2012).

The lower circulating steroid concentrations in cattle under high nutritional planes may be due to two causes: 1) there is lower steroidogenesis in follicles or CL of animals fed with high energy diets than those in restricted feeding. However, there is no study that was able to adequately measure production of ovarian steroids in cows submitted to different nutrition regimes; 2) cows ingesting large quantities of feed have higher liver blood flow (Sangsritavong et al. 2002, Vasconcelos et al. 2003). Consequently, steroid hormones are catabolized at greater rates, resulting in decreased circulating concentrations. Indeed, lactating dairy cows, in relation to non-lactating cows, have a twofold greater hepatic blood flow and, consequently, catabolize much more P4 and E2 (Sangsritavong et al. 2002).

Blood E2 concentration has a high positive correlation (0.57) with the proportion of cows presenting estrous behavior and intensity of estrus. Moreover, there is a high negative correlation between milk production and duration of estrus (-0.45; Lopez et al. 2004). Thus, lactating dairy cows have shorter duration of estrus than heifers (7.3 vs. 10.7 h; $\mathrm{P}<0.05$; Nebel et al. 1997), which compromises reproductive management strategies in dairy herds.

In relation to fertility, a longer time between luteolysis and ovulation, or a longer period of follicle dominance may affect embryo quality. Cerri et al. (2009) reported that almost $80 \%$ of embryos were grades 1 or 2 (i.e., considered viable; Robertson \& Nelson 1998) in cows with a 5.5 to $6.0 \mathrm{~d}$ period of follicle dominance, whereas only $45 \%$ of embryos were considered viable in cows with a period of dominance lasting 8.5 to $11.5 \mathrm{~d}$. Moreover, there is a negative correlation ( $r=-0.22$ ) between the period of follicle dominance and conception rate (Bleach et al. 2004). In our studies comparing embryo quality from high producing lactating Holstein versus pubertal heifers or nonlactating cows, a lower embryo viability was detected in lactating cows (Sartori et al. 2002b). Among those embryos recovered $5 \mathrm{~d}$ after Al from single ovulation 
lactating cows, only $48 \%$ were considered viable, whereas nulliparous heifers and nonlactating dairy cows yielded $72 \%$ (summer) and $82 \%$ (winter) of viable embryos, respectively. Moreover, during summer, lactating dairy cows had compromised fertilization compared to heifers (55\% vs $100 \%$, respectively).

In general, lower blood P4 concentration in cows caused by high feed intake compromises fertility. Cows with lower blood P4 concentrations during the pre-ovulatory follicle growth before Al had reduced fertility (Folman et al. 1973, Fonseca et al. 1983, Bisinotto et al. 2010a,) and supplementation of P4 prior to Al increased conception rate (Folman et al. 1990, Wehrman et al. 1993, Bisinotto et al. 2013). Low serum P4 concentration allows increased pulse frequency of LH (Roberson et al. 1989, Adams et al. 1992), causing premature maturation of the oocyte (Revah \& Butler 1996) with a resulting decrease in oocyte quality at the time of ovulation, and consequently, low embryo quality (Ahmad et al. 1995). Reduced P4 concentration after $\mathrm{Al}$ also is associated with reduced fertility (Lukaszewska \& Hansel 1980, Ahmad et al. 1995, Larson et al. 1997). Consistently, treatments to reduce P4 during early diestrus impaired embryo development (Lonergan 2011).

Likewise, alteration in circulating E2 concentrations may affect fertilization or transport of an embryo/ovum. Moreover, estrogen-dependent secretory proteins are postulated to be an essential part of a supportive environment for sperm capacitation, fertilization and early embryonic development. An altered oviductal microenvironment in cows bearing a persistent dominant follicle has been observed (Binelli et al. 1999). It was postulated that this inappropriate microenvironment contributes to the decreased fertility observed in cows with persistent follicles. Furthermore, excessive exposure to E2 was suggested to be deleterious to the oocyte and early embryo (Inskeep 2004).

Collectively, evidence is accumulating from different research groups and experimental models to suggest that the high-yield, intensively managed, modern dairy cow has abnormally low concentrations of E2 and $\mathrm{P} 4$ at different reproductive windows, and this condition negatively impacts fertility. As described in the next sections, positive fertility responses have resulted from using FTAI protocols as tools to supplement the limiting concentrations of steroid hormones at specific moments of the reproductive cycle.

\section{Controlling P4 concentrations during follicle growth to increase oocyte quality and to increase efficiency of $\mathrm{CL}$ regression prior to $\mathrm{Al}$}

One important premise of FTAI is that protocols can be initiated in cows at random stages of the estrous cycle. However, early in protocol development it was clear that fertility to the protocols varied according to changes in concentrations of P4 through the protocol (Moreira et al. 2000). Bisinotto et al. (2010a) indicated that fertility was greater when follicle development occurred under greater $\mathrm{P} 4$ concentrations, such as those present in the second wave of follicle development versus the first wave. Explanations for these findings are multifactorial and may involve effects of supplemental P4 on quality of the oocyte and resulting embryo, as well as function of the reproductive tract. For example, Rivera et al. (2011) measured a greater proportion of excellent, good and fair quality embryos in superstimulated cows treated with supplemental P4 during the superstimulation protocol. Additionally, Cerri et al. (2011) showed altered dynamics of endometrial steroid receptors and magnitude of oxytocin-stimulated PGF release when cows had programmed ovulatory follicle development under contrasting concentrations of P4. It was suggested that changes associated with follicle growth under low P4 concentrations could disturb negatively the processes of pregnancy recognition and thereby fertility. 
Another critical event involves induction of complete luteolysis. It is now well accepted that slight elevations in $\mathrm{P} 4$ concentrations near the time of $\mathrm{Al}$, due to lack of complete $\mathrm{CL}$ regression, result in major reductions in fertility of dairy cattle (Souza et al. 2007, Brusveen et al. 2009, Martins et al. 2011b). E2/P4-based protocols are used widely in countries that do not have governmental regulatory restrictions on the use of these pharmaceutical drugs, such as Brazil, Argentina, Australia and Japan. Such protocols consist of injecting E2 concomitant with the insertion of a source of releasable progestin to induce follicle turnover, then removal of the progestin source after 7 to 9 days concurrently with induction of luteolysis (i.e., injecting PGF), and finally induction of ovulation. In E2/P4-based protocols, one possible strategy for more efficacious $C L$ regression is to advance the PGF injection in relation to progestin withdrawal. There are at least two advantageous outcomes from this practice. One is to allow more time for endogenous P4 to decrease and second is to allow for a more uniform decline in P4 among cows. Pereira et al. (2013a) evaluated whether there would be an effect on fertility to FTAI or timed embryo transfer (TET) by changing the timing of treatment with PGF (injected PGF on d 7 vs. $d$ 8) during an 8d E2/P4-based program for synchronized ovulation. A higher fertility in the $d 7$ PGF treated group was observed at $d 28$ and $d 60$ diagnoses of pregnancy for both primiparous and multiparous cows. The magnitude of the response to earlier treatment with PGF was quite impressive with over a 50\% improvement in day $30 \mathrm{P} / \mathrm{Al}$ (i.e., 32.9 vs. 20.6\%). In contrast, the effects of timing of PGF treatment were more subtle in the cows that received TET with only a $13 \%$ improvement in pregnancies/timed embryo transfer (P/TET) between cows that received PGF on $\mathrm{d} 7$ vs. $\mathrm{d} 8$ (i.e., 47.0 vs. 40.7\%). Thus, it appears that there is a dramatic effect of advancing the PGF injection that is likely mediated through a series of events such as gamete maturation and transport, fertilization, early embryo development, and changes in the uterine or hormonal environment that manifests itself after embryo transfer on $\mathrm{d} 7$.

One critical point is how low P4 concentration must be at the moment of Al not to be deleterious to pregnancy. Pereira et al. (2013b) used ROC curves and selected two important cut-offs of $\leq 0.09 \mathrm{ng} / \mathrm{mL}$ at FTAI and $\leq 0.21 \mathrm{ng} / \mathrm{mL}$ for TET (i.e., at $7 \mathrm{~d}$ before TET). The fertility results gave strong support for these values as definitions for luteolysis. Cows bred by FTAI had much greater fertility if they had P4 concentrations $\leq 0.09 \mathrm{ng} / \mathrm{mL}$ at the time of FTAI $(34.1 \%)$ vs cows with greater concentrations (20.2\%). Interestingly, the $0.09 \mathrm{ng} / \mathrm{mL}$ did not have an effect on fertility in TET, whereas there was a $50.5 \%$ decrease in fertility in TET cows with P4 $>0.21 \mathrm{ng} / \mathrm{mL}$ on day 10 of the protocol (7 d before TET). Brusveen et al. (2009), Santos et al. (2010), Martins et al. (2011a and 2011b) and Giordano et al. (2012) suggested that the highest $\mathrm{P} 4$ at $\mathrm{Al}$ not to adversely affect pregnancy outcome was $0.4,0.5$ and $0.24 \mathrm{ng} / \mathrm{mL}$, respectively. These concentrations were superior to the $0,09(\mathrm{ng} / \mathrm{mL})$ established by Pereira et al. (2013b). Variations on these values are probably due to differences in protocols and experimental designs, but it is clear that low P4 values at insemination benefit fertility of FTAI programs.

Explanations for the benefit of minimal concentrations of $\mathrm{P} 4$ at $\mathrm{Al}$ include the greater rates of ovulation of cows presenting less than $0.1 \mathrm{ng} / \mathrm{ml} \mathrm{P4}$ at Al (79.8 vs. 60.6\%; Monteiro Jr et al. 2012). Accordingly, P/AI were 49.0 vs. $27.3 \%$ for cows presenting P4 concentrations less than $0.1 \mathrm{ng} /$ $\mathrm{mL}$ versus between 0.1 and $0.3 \mathrm{ng} / \mathrm{mL}$, respectively. Another mechanistic observation includes the effect of $\mathrm{P} 4$ on oviduct function. The oviduct epithelium undergoes dramatic morphological and functional changes throughout the estrous cycle (Abe \& Oikawa 1993). Changes include variations in the expression of oviductal mRNA coding for steroid receptors (PGR and ESR1) and epithelial markers (i.e., MUC16, OVGP1, HSP90B1) and in the sperm-binding capacity of the epithelium in culture (Chen et al. 2013) . At simulated estrus, in vitro, more sperm were bound compared to simulated diestrus. Thus, residual $\mathrm{P} 4$ resulting from incomplete luteolysis at AI could cause a decreased sperm binding and fertilizing capacity, contributing to decreased fertility. 


\section{Estrogen priming during proestrus benefits $\mathrm{P} / \mathrm{Al}$ and enhance conceptus survival}

Programming of a coordinated sequence of ovarian events is necessary for successful synchronization of fertile ovulations. Ovarian events involve release of steroid hormones for sufficient duration and magnitude. The intense steroid catabolism associated with high milk synthesis reduces steroid circulating concentrations, and this is probably a contributory condition associated with the modern dairy cow sub-fertility syndrome. Portions of the estrous cycle that are critically affected by this phenomenon are proestrus and estrus. Indeed, high producing dairy cows display estrous behavior in much less frequency and intensity than lower producers (Lopez et al. 2004). Estrous behaviour results from hypothalamic priming by E2 released by the dominant follicle in the absence of P4 (i.e., after luteolysis). Thus, diminished estrous behaviour likely results from lower circulating concentrations of E2 at expected proestrus-estrus. Most importantly, the presence of estrous behaviour is associated positively with pregnancy success in both beef (Perry et al. 2005, Perry et al. 2007, Sá Filho et al. 2010, Sá Filho et al. 2011) and dairy cows (Galvão et al. 2004, Souza et al. 2007, Hillegass et al. 2008, Pereira et al. 2014). Moreover, greater endometrial thickness, due to higher circulating E2 near FTAI, also was associated with improved fertility in high-producing dairy cows (Souza et al. 2011). The collective beneficial effects to fertility of sufficiently elevated E2 during the proestrus period stimulated the adoption of strategies to achieve this outcome within FTAI programs. Strategies have included the addition of E2 to the end of the Ovsynch protocol (Souza et al. 2007), stimulation of ovulation using E2 injections (Pancarci et al. 2002, Cerri et al. 2004, Stevenson et al. 2004), and increasing the interval between the luteolytic injection (PGF) and the time of expected ovulation (Pereira et al. 2013b). A longer proestrus period allows a longer period for the pre-ovulatory follicle to grow and allowing it to achieve full estrogenic capacity. Indeed, in the experiment by Pereira and collaborators (2013b), increased fertility and decreased pregnancy losses between days 30 and 60 were associated probably not only with the more complete luteolysis reported for cows receiving advanced PGF injections but also due to a longer proestrus period. A summary of results from various studies with Bos taurus beef cattle completed in the laboratory of Michael Day (Bridges et al. 2010) indicated that fertility increased consistently as time from PGF until GnRH increased. Similarly, in suckled Bos indicus beef cattle with a $\mathrm{CL}$ at $4 \mathrm{~d}$ before FTAI, Meneghetti et al. (2009) reported an increase in P/AI (50.3 vs. 36.1\%) when PGF was injected $4 \mathrm{~d}$ before FTAI rather than $2 \mathrm{~d}$ before FTAI, which was the time of CIDR removal and ECP treatment in this protocol. In nonlactating Bos indicus beef cattle (Peres et al. 2009) the treatment with PGF $4 \mathrm{~d}$ before FTAI resulted in lower P4 concentrations on $\mathrm{d}$ of CIDR removal, a larger follicle at FTAI, increased percentage of cows that ovulated to the protocol (85.4\% vs. $77.0 \%$ ), and increased P/AI (52.0 vs. $36.4 \%$ for all cows; 60.9 vs. $47.2 \%$ for cows that ovulated) compared to cows treated with PGF $2 \mathrm{~d}$ before FTAI. In grazing dairy cows that were presynchronized with two PGF treatments (Presynch), reducing the interval from first GnRH until PGF from 7d to 5d increased P/Al in a 5d Cosynch FTAI protocol (Bisinotto et al. 2010b, Ribeiro et al. 2012). Pereira et al. (2014) treated lactating Holstein cows with E2/ P4-based protocols with different durations (8 vs. $9 \mathrm{~d}$ ). Protocols were identical except that interval between the luteolytic PGF injection and the ovulatory ECP injection was 1 vs. $2 \mathrm{~d}$, respectively. Although $\mathrm{P} / \mathrm{Al}$ was similar between groups, pregnancy losses between 32 and $60 \mathrm{~d}$ of pregnancy were decreased $(P=0.03)$ in the $9 \mathrm{~d}(7.8 \%)$ compared to the $8 \mathrm{~d}(15.2 \%)$ protocol.

Pereira et al. (2013a) tested the concept of using E2 to induce ovulation in FTAI protocols on dairy cows subjected to summer heat stress. They compared an Ovsynch-type protocol (the 5d Cosynch; Bisinotto et al. 2010b, Santos et al. 2010) and an E2/P4-based protocol, designed to have similar ages of the ovulatory follicle in synchronized cows. There was increased P/AI 
with the E2/P4 protocol (25.6\%) compared with the $5 \mathrm{~d}$ Cosynch protocol (17.7\%) and primary reason for the reduced $\mathrm{P} / \mathrm{Al}$ in the $5 \mathrm{~d}$ Cosynch protocol was the high pregnancy loss between days 32 and 60 in this group (21.7\%) compared with cows in the E2/P4 protocol (6.7\%). Finally, although authors did not measure circulating E2 in this trial, the physiological effects of elevated E2 are clearly manifested in the greater expression of estrus in the cows in the E2/ P4 protocol (62.8\%) compared with the 5d Cosynch protocol (43.4\%).

Similar to previous studies, Pereira et al. (2013a) observed that follicle size had a positive effect on P/Al in both protocols using either the $32 \mathrm{~d}$ or $60 \mathrm{~d}$ pregnancy diagnosis. A particularly intriguing finding was that smaller follicles were associated with a greatly increased pregnancy loss from 32 to $60 \mathrm{~d}$ for cows in the $5 \mathrm{~d}$ Cosynch protocol, but not for cows receiving the E2/P4 protocol. Thus, increased circulating E2 near Al may produce changes that reduce pregnancy loss from 32 to $60 \mathrm{~d}$ after Al during summer heat stress. Perry et al. (2005) reported that GnRHinduced ovulation of small follicles $(<11.3 \mathrm{~mm})$ in beef cows was associated with decreased pregnancy rates and decreased circulating concentrations of E2 at Al and greater pregnancy loss, although pregnancy outcome following spontaneous estrus and ovulation was not affected by follicle diameter. These data are consistent with the concept that greater circulating E2 near Al may reduce pregnancy loss at the later embryonic stages (between 32 to $60 \mathrm{~d}$ after Al). However, it should be noted that response to treatments may be affected by season of the year.

Collectively for this and the previous section, the improved fertility with a longer time period from induction of luteolysis with PGF until induction of synchronized ovulation could be related to greater time for CL regression and thus lower P4 at FTAI or, alternatively, greater time for follicle growth in the absence of P4, increased ovulatory follicle size, and increased E2 before synchronized ovulation.

\section{P4 priming during early diestrus}

The pre-implantation window of gestation in cattle (i.e., three first weeks) is greatly susceptible to failure (Sartori et al. 2002b, Santos et al. 2004, Diskin et al. 2012). During this period, the conceptus relies on endometrial histotrophic nutrition to develop (Spencer \& Gray 2006, Bazer et al. 2011). The endometrial transcriptome, secretome and, consequently, production and composition of histotroph are regulated by $\mathrm{P} 4$ concentrations in the pre-implantation period (Forde et al. 2009). Indeed, supplementation of P4 after ovulation stimulates conceptus elongation (Carter et al. 2008), and reduction in P4 concentrations causes the opposite effect (Forde et al. 2011). As mentioned previously, intense steroid catabolism, associated with high dry matter intake needed to support milk production of the dairy cow, acts to decrease concentrations of $\mathrm{P} 4$ at this critical window and thereby contributes to the low fertility (Demetrio et al. 2007). Thus, it is rational that strategies to supplement $\mathrm{P} 4$ post-ovulation may benefit P/AI.

A number of strategies to supplement P4 post-ovulation have been attempted, and effects on fertility are variable. Strategies include inducing the ovulation of the first wave follicle to cause the formation of an accessory $C L$ to provide additional P4, treating cows with exogenous sources of P4 after $\mathrm{Al}$, and stimulating the P4 secreting ability of the original $\mathrm{CL}$. Regarding the formation of accessory CL, Santos et al. (2001) administered hCG to dairy cows $5 \mathrm{~d}$ after $\mathrm{Al}$ and reported increased P/AI as compared to controls (45.8\% vs. 38.7\%). More recently, Nascimento et al. (2013b), found a positive effect on P/AI in primiparous cows treated with hCG $5 \mathrm{~d}$ after $\mathrm{Al}(49.7 \%$ vs. 39.5\%) but not multiparous (35.7\% vs. 36.0\%, respectively). Vasconcelos et al. (2011) evaluated the effects of treatments with hCG or GnRH at $7 \mathrm{~d}$ after induced ovulation on reproductive performance of lactating dairy cows submitted to FTAI or ET. 
Cows were assigned randomly to receive, on $d 7$, either no additional treatments (Control; FTAI: $\mathrm{n}=156$; TET: $\mathrm{n}=126)$, a $100 \mu \mathrm{g}$ i.m. injection of GnRH (GnRH; FTAI: $\mathrm{n}=155$; TET: $\mathrm{n}=124)$, or a 2,500 IU i.m. injection of hCG (hCG; FTAI: $n=151$; TET: $n=122$ ). There were effects of post-breeding treatments on the percentages of pregnant cows at TET on d 28 (Control: $38.1 \%$; GnRH: 52.4\%; hCG: $45.1 \%$ ) and on d 60 (Control: 32.5\%; GnRH: 41.1\%; hCG: 38.5\%), but no effects of post-breeding treatments were detected on the percentages of pregnant cows at FTAI on d 28 (Control: 30.1\%; GnRH: 32.2\%; hCG: 32.4\%) nor on d 60 (Control: 25.6\%; GnRH: $27.1 \%$; hCG: $29.8 \%$ ). It was concluded that treatment with $\mathrm{GnRH}$ or hCG at $7 \mathrm{~d}$ after induced ovulation increased conception rates in lactating dairy cows submitted to TET, but not in cows submitted to FTAI. Collectively, there is no consistently positive response to the additional P4 provided by the CL resulting from the ovulation of the first wave dominant follicle. Responses vary according to day after induction of ovulation in which $\mathrm{P} 4$ increases relative to non-treated controls and parity. Specifically, if the additional P4 becomes available at later moments (e.g., such as when hCG is injected at day 7 after induced ovulation), it will affect the uterus at a stage in which it may no longer be limiting to pregnancy success. In fact, Demetrio et al. (2007) reported that there was a positive association between P4 concentrations on $\mathrm{d} 7$ after Al and P/AI for lactating cows but there was no association between P4 concentrations on that same day for cows receiving embryo transfer. More recently, researchers started to target supplementation of P4 at earlier days after AI.

Some studies have supplemented cows with exogenous P4 and observed an improvement in P/AI. For example, Holstein cows had $48 \% \mathrm{P} / \mathrm{AI}$, when a CIDR was used between $\mathrm{d} 3.5$ and 10 after $\mathrm{Al}$ as compared to $35 \%$ when cows were not supplemented (Larson et al. 2007). Likewise, Monteiro Jr et al. (2014) supplemented P4 between d4 and 17, with either a single CIDR or a single CIDR with an additional CIDR added at day 7 and both groups having device (s) withdrawn at the end of D17. Supplementation failed to alter P/AI at either day 34 or day 62. However, a single CIDR inserted at day 4 and removed at day 17 increased P/AI in cows that were FTAI but not in cows that were inseminated at detected estrus. The two supplemental CIDR sequence did not influence P/AI in cows inseminated at detected estrus or FTAI. However, with an E2/P4 based protocol, Monteiro Jr et al. (2013) did not detect improvement in P/AI after CIDR supplementation between d 3 and 17 after AI in Holstein and cross-bred (Holstein $x$ Gir) cows. Causes for the lack of clear effects of supplementation of P4 through exogenous sources on P/AI are not known. One might expect that the extra P4 could affect original CL formation and function, but this was not supported by the data of Monteiro Jr et al. (2013) and Souza et al. (2013) for dairy cattle, nor from Pugliesi et al. (2014) for beef cattle. In the study of Pugliesi et al. (2014), P4 supplementation via intramuscular injection of 300 mg P4 in a slow release formulation given two days after ovulation, induced functional and structural regression of the CL 4 days earlier than vehicle-injected controls. It seems there is a paradoxical effect of supplementing P4, as described by O'Hara et al. (2014). On one hand P4 induces alterations in histotroph composition and quantity to stimulate conceptus growth. On the other hand, P4 supplementation advances luteolysis leading to embryo mortality. The outcome of this dilemma is the inconsistent results of experiments in terms of P/AI in response to P4 supplementation.

One final strategy to supplement P4 post AI is through the stimulation of the secretory ability of the $\mathrm{CL}$ originated from the synchronized ovulation. A recent paper from Maillo et al. (2013) reported that an injection of hCG $2 \mathrm{~d}$ after estrus increased the area of the original $\mathrm{CL}$ as well as its ability to produce P4 from days 6 to 11, in comparison to placebo injected controls. Although promising, this strategy has not been tested in fertility trials yet. Additional circulating P4 during this window may be beneficial to conceptus development and survival. Finally, strategies to effectively reduce P4 concentrations at AI and to stimulate E2 priming during proestrus-estrus, such as described in the previous sections, stimulate growth of the 
pre-ovulatory follicle and growth and function of the subsequent CL (Vasconcelos et al. 2001). Furthermore, such strategies result in increased P/AI.

\section{"Pro-fertility" protocols}

According to what was discussed above, an ideal FTAI protocol should attend to all the premises to provide adequate hormonal milieu for oocyte quality, ovulation, gamete transport as well as embryo development. To serve as a reference, we suggest "pro-fertility" protocols that incorporate the concepts described in this paper, and compare them to other FTAI protocols (Fig. 1 and Table 1). One of them is the Double-Ovsynch protocol, described by Souza et

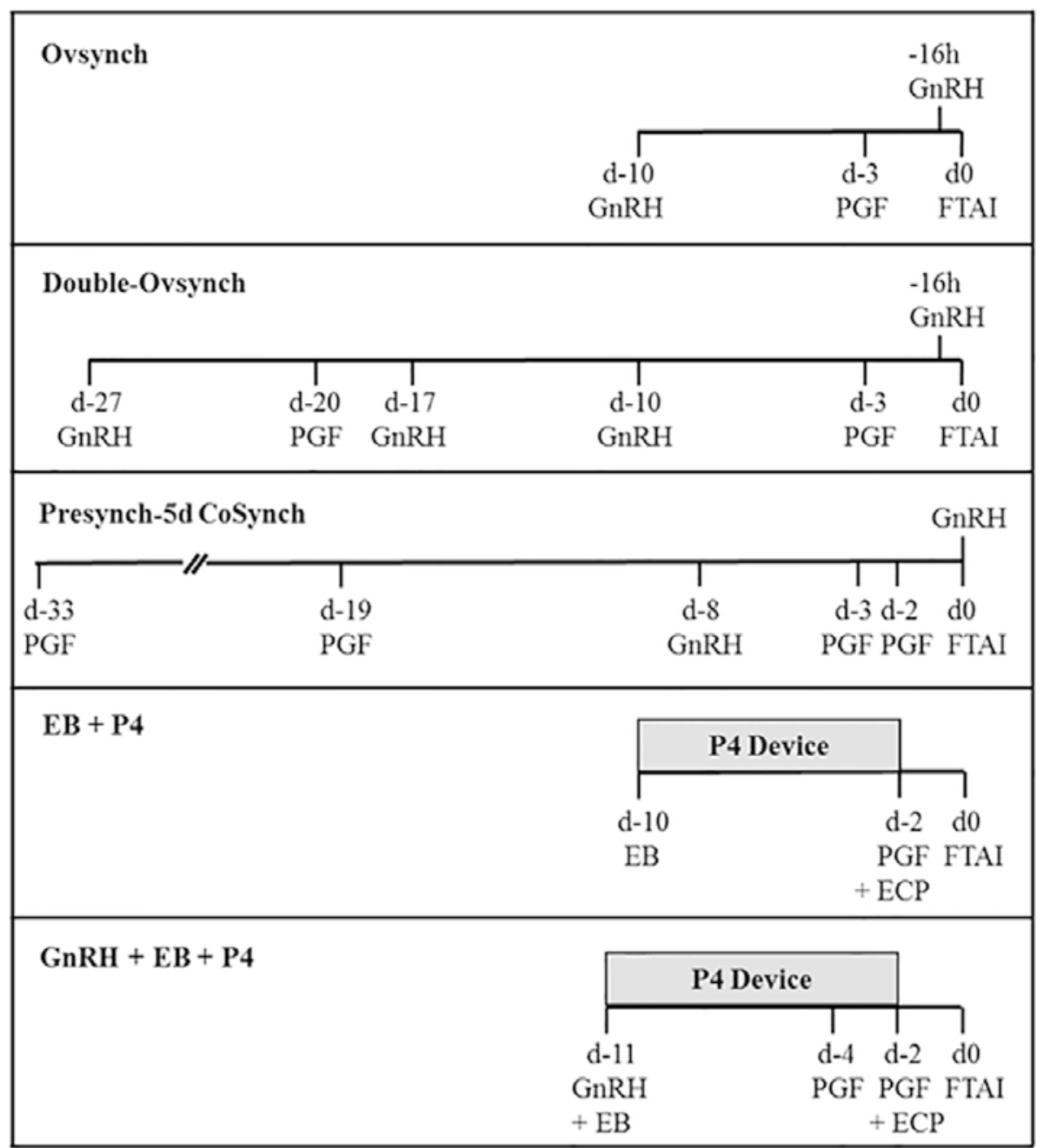

Fig. 1. Schematic diagrams of FTAI protocols for dairy cows (please see text for details). $\mathrm{GnRH}=$ Gonadotropin-releasing hormone; PGF = Prostaglandin F2 $\alpha$; EB = Estradiol benzoate; $\mathrm{ECP}=$ Estradiol cypionate; $\mathrm{P} 4$ device $=$ Intravaginal device for controlled progesterone release; $\mathrm{FTAI}=$ Fixed-time artificial insemination. 
Table 1. Analysis of Ovsynch (Pursley et al., 1995), Double-Ovsynch (Souza et al. 2009), Presynch-5d CoSynch (Santos et al., 2010), EB (estradiol benzoate) + P4 (Souza et al., 2009) and GnRH + EB + P4 (Pereira et al. 2013c) protocols based on concepts applied to novel protocols for lactating dairy cows.

\begin{tabular}{|c|c|c|c|c|c|}
\hline & \multicolumn{5}{|c|}{ Protocols } \\
\hline & Ovsynch & $\begin{array}{l}\text { Double- } \\
\text { Ovsynch }\end{array}$ & $\begin{array}{l}\text { Presynch- } \\
5 \mathrm{~d} \text { Cosynch }\end{array}$ & $E B+P 4$ & $\begin{array}{l}\mathrm{GnRH}+ \\
\mathrm{EB}+\mathrm{P} 4\end{array}$ \\
\hline Shorter follicle dominance period & & $\mathrm{x}$ & $\mathrm{x}$ & $\mathrm{x}$ & $x$ \\
\hline Higher P4 during follicle development & & $\mathrm{x}$ & $\mathrm{x}$ & & $\mathrm{X}$ \\
\hline Total reduction of $\mathrm{P} 4$ concentration prior to $\mathrm{Al}$ & & & $\mathrm{x}$ & & $\mathrm{X}$ \\
\hline Estradiol priming of sufficient duration and intensity & & & & $\mathrm{x}$ & $\mathrm{X}$ \\
\hline Early and prominent post-ovulatory rise in $\mathrm{P} 4$ * & & & & & \\
\hline
\end{tabular}

*None of the above protocols provides an ideal post-ovulatory rise in P4 for adequate embryo development in the high-producing dairy cow.

al. (2008), whose advantages were very well discussed by Wiltbank et al. (2011). Another protocol that has been evaluated with similar results to the Double-Ovsynch is the Presynch-5d Cosynch (Santos et al. 2010; Ribeiro et al. 2012). Recently, we developed the GnRH + EB + P4 protocol, described by Pereira et al. (2013c). This protocol presents some extra features that make it very attractive, such as the association of $\mathrm{GnRH}$ with $\mathrm{EB}$ at the beginning, resulting in better wave emergence synchronization, increased $\mathrm{P} 4$ concentrations and proportion of cows with CL at PGF. The addition of an intravaginal P4 device, not only increases synchronization, but also contributes to more circulating P4 during follicle development. Finally, the use of two PGF injections would result in lower P4 at Al, increasing fertility in lactating dairy cows. In fact, Pereira et al. (2013c) performed a study with 1642 lactating Holstein cows and observed more circulating P4 during pre-ovulatory follicle development, higher percentage of cows that had luteolysis, and higher synchronization by adding $\mathrm{GnRH}$ at the onset of the protocol and an extra PGF treatment at the end of the protocol as compared to the Control protocol $(E B+$ P4). The GnRH protocol (described as $\mathrm{GnRH}+\mathrm{EB}+\mathrm{P} 4$ in Fig. 1 and Table 1) improved P/ $\mathrm{Al}$ at 32 (40 vs. 32\%) and $60 \mathrm{~d}$ (33 vs. 26\%), compared to Control.

Table 1 provides a subjective analysis comparing FTAI protocols regarding their efficiency on applying the concepts described in this review article. In this sense, the protocols that best fit these concepts are the Presynch-5d Cosynch and the $\mathrm{GnRH}+\mathrm{EB}+\mathrm{P} 4$. Although some of these protocols are having promising results, none of them adequately meets the need to provide enough circulating P4 post Al to compensate for the high clearance in high-producing cows (Table 1).

\section{Conclusions}

Current concepts, as well as future concept development, on pharmacological manipulation of the estrous cycle to synchronize ovulations must take in consideration the endocrinology of particular animal categories. For the high yield dairy cow, intense liver sex steroid catabolism results in an endocrine environment that is sub-optimal to fertility. Protocols that provide steroid supplementation at critical portions within the synchronization regime were beneficial and increased P/AI. To conclude, evidence is accumulating to support the concept that programming and coordination of the continuum of endocrine events from preovulatory follicle development to post-AI P4 effects is necessary to increase P/FTAI and reduce embryo losses. 


\section{Acknowledgements}

Brazilian granting agencies FAPESP, CAPES and CNPq for research grant support, Zoetis and Ourofino for pharmaceutical products, students and staff at the University of São Paulo and São Paulo State University for technical support, owners and staff of collaborating dairies for the use of animals and facilities and Drs. William W. Thatcher and Milo C. Wiltbank for their long term support to our programs.

\section{References}

Abe H \& Oikawa T 1993 Observations by scanning electron microscopy of oviductal epithelial cells from cows at follicular and luteal phases. Anat Rec 235 399-410.

Adams GP, Matteri RL \& Ginther OJ 1992 Effect of progesterone on ovarian follicles, emergence of follicular waves and circulating follicle-stimulating hormone in heifers. J Reprod Fertil 96 627-640.

Ahmad N, Schrick FN, Butcher RL \& Inskeep EK 1995 Effect of persistent follicles on early embryonic losses in beef cows. Biol Reprod 52 1129-1135.

Bazer FW, Spencer TE, Johnson GA \& Burghardt RC 2011 Uterine receptivity to implantation of blastocysts in mammals. Front Biosci (Schol Ed) 3 745-767.

Binelli M, Hampton J, Buhi WC \& Thatcher WW 1999 Persistent dominant follicle alters pattern of oviductal secretory proteins from cows at estrus. Biol Reprod $\mathbf{6 1}$ 127-134.

Bisinotto RS, Chebel RC \& Santos JE 2010a Follicular wave of the ovulatory follicle and not cyclic status influences fertility of dairy cows. J Dairy Sci 93 3578-3587.

Bisinotto RS, Ribeiro ES, Lima FS, Martinez N, Greco LF, Barbosa LF, Bueno PP, Scagion LF, Thatcher WW \& Santos JE 2013 Targeted progesterone supplementation improves fertility in lactating dairy cows without a corpus luteum at the initiation of the timed artificial insemination protocol. J Dairy Sci 96 2214-2225.

Bisinotto RS, Ribeiro ES, Martins LT, Marsola RS, Greco LF, Favoreto MG, Risco CA, Thatcher WW \& Santos JE $2010 \mathrm{~b}$ Effect of interval between induction of ovulation and artificial insemination (AI) and supplemental progesterone for resynchronization on fertility of dairy cows subjected to a 5-d timed Al program. J Dairy Sci 93 5798-5808.

Bleach EC, Glencross RG \& Knight PG 2004 Association between ovarian follicle development and pregnancy rates in dairy cows undergoing spontaneous oestrous cycles. Reproduction 127 621-629.

Bridges GA, Mussard ML, Burke CR \& Day ML 2010 Influence of the length of proestrus on fertility and endocrine function in female cattle. Anim Reprod Sci 117 208-215.

Brusveen DJ, Souza AH \& Wiltbank MC 2009 Effects of additional prostaglandin F2alpha and estradiol-17beta during Ovsynch in lactating dairy cows. J Dairy Sci 92 1412-1422.

Carter F, Forde N, Duffy P, Wade M, Fair T, Crowe MA, Evans AC, Kenny DA, Roche JF \& Lonergan P 2008
Effect of increasing progesterone concentration from Day 3 of pregnancy on subsequent embryo survival and development in beef heifers. Reprod Fertil Dev 20 368-375.

Cerri RL, Chebel RC, Rivera F, Narciso CD, Oliveira RA, Amstalden M, Baez-Sandoval GM, Oliveira LJ, Thatcher WW \& Santos JE 2011 Concentration of progesterone during the development of the ovulatory follicle: II. Ovarian and uterine responses. J Dairy Sci 94 3352-3365.

Cerri RL, Rutigliano HM, Chebel RC \& Santos JE 2009 Period of dominance of the ovulatory follicle influences embryo quality in lactating dairy cows. Reproduction 137 813-823.

Cerri RL, Santos JE, Juchem SO, Galvão KN \& Chebel RC 2004 Timed artificial insemination with estradiol cypionate or insemination at estrus in high-producing dairy cows. J Dairy Sci 87 3704-3715.

Chen S, Einspanier R \& Schoen J 2013 In vitro mimicking of estrous cycle stages in porcine oviduct epithelium cells: estradiol and progesterone regulate differentiation, gene expression, and cellular function. Biol Reprod 89(3) 54.

De la Sota RL, Lucy MC, Staples CR \& Thatcher WW 1993 Effects of recombinant bovine somatotropin (sometribove) on ovarian function in lactating and nonlactating dairy cows. J Dairy Sci 76 1002-1013.

Demetrio DG, Santos RM, Demetrio CG \& Vasconcelos JL 2007 Factors affecting conception rates following artificial insemination or embryo transfer in lactating Holstein cows. J Dairy Sci 90 5073-5082.

Diskin MG, Parr MH \& Morris DG 2012 Embryo death in cattle: an update. Reprod Fertil Dev 24 244-251.

Folman Y, Kaim M, Herz Z \& Rosenberg M 1990 Comparison of methods for the synchronization of estrous cycles in dairy cows. 2. Effects of progesterone and parity on conception. J Dairy Sci 73 2817-2825.

Folman Y, Rosenberg M, Herz Z \& Davidson M 1973 The relationship between plasma progesterone concentration and conception in post-partum dairy cows maintained on two levels of nutrition. J Reprod Fertil 34 267-278.

Fonseca FA, Britt JH, McDaniel BT, Wilk JC \& Rakes AH 1983 Reproductive traits of Holsteins and Jerseys. Effects of age, milk yield, and clinical abnormalities on involution of cervix and uterus, ovulation, estrous cycles, detection of estrus, conception rate, and days open. J Dairy Sci $\mathbf{6 6}$ 1128-1147.

Forde N, Beltman ME, Duffy GB, Duffy P, Mehta JP, O'Gaora P, Roche JF, Lonergan P \& Crowe MA 2011 
Changes in the endometrial transcriptome during the bovine estrous cycle: effect of low circulating progesterone and consequences for conceptus elongation. Biol Reprod 84 266-278.

Forde N, Carter F, Fair T, Crowe MA, Evans AC, Spencer TE, Bazer FW, McBride R, Boland MP, O'Gaora P, Lonergan P \& Roche JF 2009 Progesterone-regulated changes in endometrial gene expression contribute to advanced conceptus development in cattle. Biol Reprod 81 784-794.

Galvão KN, Santos JE, Juchem SO, Cerri RL, Coscioni AC \& Villaseñor M 2004 Effect of addition of a progesterone intravaginal insert to a timed insemination protocol using estradiol cypionate on ovulation rate, pregnancy rate, and late embryonic loss in lactating dairy cows. J Anim Sci 82 3508-3517.

Giordano JO, Wiltbank MC, Guenther JN, Pawlisch R, Bas S, Cunha AP \& Fricke PM 2012 Increased fertility in lactating dairy cows resynchronized with DoubleOvsynch compared with Ovsynch initiated $32 \mathrm{~d}$ after timed artificial insemination. J Dairy Sci 95 639-653.

Hillegass J, Lima FS, Sá Filho MF \& Santos JE 2008 Effect of time of artificial insemination and supplemental estradiol on reproduction of lactating dairy cows. J Dairy Sci 91 4226-4237.

Inskeep EK 2004 Preovulatory, postovulatory, and postmaternal recognition effects of concentrations of progesterone on embryonic survival in the cow. J Anim Sci 82 E-Suppl E24-39.

Larson SF, Butler WR \& Currie WB 1997 Reduced fertility associated with low progesterone postbreeding and increased milk urea nitrogen in lactating cows. J Dairy Sci 80 1288-1295.

Larson SF, Butler WR \& Currie WB 2007 Pregnancy rates in lactating dairy cattle following supplementation of progesterone after artificial insemination. Anim Reprod Sci 102 172-179.

Lonergan P 2011 Influence of progesterone on oocyte quality and embryo development in cows. Theriogenology $\mathbf{7 6}$ 1594-1601.

Lopez H, Satter LD \& Wiltbank MC 2004 Relationship between level of milk production and estrous behavior of lactating dairy cows. Anim Reprod Sci 81 209-223.

Lukaszewska J \& Hansel W 1980 Corpus luteum maintenance during early pregnancy in the cow. J Reprod Fertil 59 485-493.

Maillo V, Duffy P, O'Hara L, de Frutos C, Kelly AK, Lonergan P \& Rizos D 2013 Effect of hCG administration during corpus luteum establishment on subsequent corpus luteum development and circulating progesterone concentrations in beef heifers. Reprod Fertil Dev. 26 367-374

Martins JP, Policelli RK, Neuder LM, Raphael W \& Pursley JR 2011a Effects of cloprostenol sodium at final prostaglandin $\mathrm{F} 2 \alpha$ of Ovsynch on complete luteolysis and pregnancy per artificial insemination in lactating dairy cows. J Dairy Sci 94 2815-2824.

Martins JP, Policelli RK \& Pursley JR 2011b Luteolytic effects of cloprostenol sodium in lactating dairy cows treated with G6G/Ovsynch. J Dairy Sci 94 2806-2814.
Meneghetti M, Sá Filho OG, Peres RF, Lamb GC \& Vasconcelos JL 2009 Fixed-time artificial insemination with estradiol and progesterone for Bos indicus cows I: basis for development of protocols. Theriogenology 72 179-189.

Monteiro Jr PLJ, Nascimento AB, Prata AB, Pontes GCS, Fernandes GO, Melo LF, Silva FLM, Oliveira LH, Wiltbank MC \& Sartori R 2013. Effect of supplementation of progesterone after $\mathrm{Al}$ in corpus luteum formation and conception rate of dairy cows. In: XXVII Annual Meeting of the Brazilian Embryo Technology Society (SBTE) 2013, Praia do Forte. Proceedings: Anim Reprod 10(3) 480 Abstract.

Monteiro Jr PLJ, Ribeiro ES, Maciel RP, Dias ALG, Solé Jr. E, Lima FS, Bisinotto RS, Thatcher WW, Sartori R \& Santos JEP 2014 Effects of Supplemental Progesterone After AI on Expression of Interferon-Stimulated Genes and Fertility in Dairy Cows. J Dairy Sci, In press.

Monteiro Jr PLJ, Rodrigues TN, Silva FLM, Borsato M, Surjus RS, Prata AB, Silva LD, Mourão GB, Wiltbank MC \& Sartori R 2012 Evaluation of timed artificial insemination protocols in dairy cattle: Presynchronization with $\mathrm{GnRH}$, increasing estradiol benzoate, and impediments to success during the protocol. In: XXVI Annual Meeting of the Brazilian Embryo Technology Society (SBTE) 2012, Foz do Iguaçu. Proceedings: Anim Reprod 9(3) 541 Abstract.

Moreira F, de la Sota RL, Diaz T \& Thatcher WW 2000 Effect of day of the estrous cycle at the initiation of a timed artificial insemination protocol on reproductive responses in dairy heifers. J Anim Sci 78 1568-1576.

Nascimento AB, Bender RW, Souza AH, Ayres H, Araujo RR, Guenther JN, Sartori R \& Wiltbank MC 2013b Effect of treatment with human chorionic gonadotropin on day 5 after timed artificial insemination on fertility of lactating dairy cows. J Dairy Sci 96 2873-2882.

Nascimento AB, Souza AH, Pontes G, Wiltbank MC \& Sartori R 2013a. Assessment of systematic breeding programs: A comparison between Al after estrus detection and timed $\mathrm{Al}$ in lactating dairy cows. I Anim Sci 91(E-suppl. 2) 594-595 Abstract.

Nebel RL, Jobst SM, Dransfield MBG, Pansolfi SM \& Bailey TL 1997 Use of a radio frequency data communication system, HeatWatch ${ }^{\circledR}$, to describe behavioral estrus in dairy cattle. J Dairy Sci 80(Suppl. 1) 151 Abstract

O'Hara L, Forde N, Carter F, Rizos D, Maillo V, Ealy AD, Kelly AK, Rodriguez P, Isaka N, Evans AC \& Lonergan P 2014 Paradoxical effect of supplementary progesterone between Day 3 and Day 7 on corpus luteum function and conceptus development in cattle. Reprod Fertil Dev 26 328-336.

Pancarci SM, Jordan ER, Risco CA, Schouten MJ, Lopes FL, Moreira F \& Thatcher WW 2002 Use of estradiol cypionate in a presynchronized timed artificial insemination program for lactating dairy cattle. J Dairy Sci 85 122-131.

Pereira MH, Rodrigues AD, De Carvalho RJ, Wiltbank MC \& Vasconcelos JL 2014 Increasing length of an estradiol and progesterone timed artificial 
insemination protocol decreases pregnancy losses in lactating dairy cows. J Dairy Sci 97 1454-1464

Pereira MH, Rodrigues AD, Martins T, Oliveira WV, Silveira PS, Wiltbank MC \& Vasconcelos JL 2013a Timed artificial insemination programs during the summer in lactating dairy cows: comparison of the 5-d Cosynch protocol with an estrogen/progesterone-based protocol. J Dairy Sci 96 6904-6914.

Pereira MHC, Sanches CP, Barbosa LFSP, Costa WM, Rodrigues ADP, Guida TG, Lima FA, Veras MB, Wiltbank MC, Vasconcelos JLM 2013C Strategies to increase fertility in lactating dairy cows submitted to TAI and FTET E2/ P4 based protocols In: XXVII Annual Meeting of The Brazilian Embryo Technology Society (SBTE) 2013, Praia do Forte. Proceedings: Anim Reprod 10 (3) 473 Abstract.

Pereira MH, Sanches CP, Guida TG, Rodrigues AD, Aragon FL, Veras MB, Borges PT, Wiltbank MC \& Vasconcelos JL 2013b Timing of prostaglandin F2 $\mathbf{D}$ treatment in an estrogen-based protocol for timed artificial insemination or timed embryo transfer in lactating dairy cows. J Dairy Sci 96 2837-2846.

Peres RF, Claro I, Sá Filho OG, Nogueira GP \& Vasconcelos JL 2009 Strategies to improve fertility in Bos indicus postpubertal heifers and nonlactating cows submitted to fixed-time artificial insemination. Theriogenology $\mathbf{7 2}$ 681-689.

Perry GA, Smith MF, Lucy MC, Green JA, Parks TE, MacNeil MD, Roberts AJ \& Geary TW 2005 Relationship between follicle size at insemination and pregnancy success. Proc Natl Acad Sci U S A 102 5268-5273.

Perry GA, Smith MF, Roberts AJ, MacNeil MD \& Geary TW 2007 Relationship between size of the ovulatory follicle and pregnancy success in beef heifers. I Anim Sci 85 684-689.

Pugliesi G, Oliveria M, Scolari S, Lopes E, Pinaffi F, Miagawa B, Paiva Y, Maio J, Nogueira G \& Binelli M 2014 Corpus luteum development and function after supplementation of long-acting progesterone during the early luteal phase in beef cattle. Reprod Domest Anim 49 85-91.

Pursley JR, Mee MO \& Wiltbank MC 1995 Synchronization of ovulation in dairy cows using PGF2alpha and GnRH. Theriogenology 44 915-923.

Revah I \& Butler WR 1996 Prolonged dominance of follicles and reduced viability of bovine oocytes. I Reprod Fertil 106 39-47.

Ribeiro ES, Monteiro AP, Lima FS, Ayres H, Bisinotto RS, Favoreto M, Greco LF, Marsola RS, Thatcher WW \& Santos JE 2012 Effects of presynchronization and length of proestrus on fertility of grazing dairy cows subjected to a 5-day timed artificial insemination protocol. J Dairy Sci 95 2513-2522.

Rivera FA, Mendonça LG, Lopes G, Santos JE, Perez RV, Amstalden M, Correa-Calderón A \& Chebel RC 2011 Reduced progesterone concentration during growth of the first follicular wave affects embryo quality but has no effect on embryo survival post transfer in lactating dairy cows. Reproduction 141 333-342.

Roberson MS, Wolfe MW, Stumpf TT, Kittok RJ \& Kinder JE 1989 Luteinizing hormone secretion and corpus luteum function in cows receiving two levels of progesterone. Biol Reprod 41 997-1003.
Robertson I \& Nelson RE 1998 Certification and identification of the embryo. In.: Manual of the International Embryo Transfer Society. Stringfellow D \& Seidel SM. pp. 103134. International Embryo Transfer Society: Savoy, IL.

Sangsritavong S, Combs DK, Sartori R, Armentano LE \& Wiltbank MC 2002 High feed intake increases liver blood flow and metabolism of progesterone and estradiol17beta in dairy cattle. J Dairy Sci 85 2831-2842.

Santos JE, Narciso CD, Rivera F, Thatcher WW \& Chebel RC 2010 Effect of reducing the period of follicle dominance in a timed artificial insemination protocol on reproduction of dairy cows. J Dairy Sci 93 2976-2988.

Santos JE, Rutigliano HM \& Sá Filho MF 2009 Risk factors for resumption of postpartum estrous cycles and embryonic survival in lactating dairy cows. Anim Reprod Sci 110 207-221.

Santos JE, Thatcher WW, Chebel RC, Cerri RL \& Galvão KN 2004 The effect of embryonic death rates in cattle on the efficacy of estrus synchronization programs. Anim Reprod Sci 82-83 513-535.

Santos JE, Thatcher WW, Pool L \& Overton MW 2001 Effect of human chorionic gonadotropin on luteal function and reproductive performance of high-producing lactating Holstein dairy cows. J Anim Sci 79 2881-2894.

Sartori R, Haughian JM, Shaver RD, Rosa GJ \& Wiltbank MC 2004 Comparison of ovarian function and circulating steroids in estrous cycles of Holstein heifers and lactating cows. J Dairy Sci 87 905-920.

Sartori R, Rosa GJ \& Wiltbank MC 2002a Ovarian structures and circulating steroids in heifers and lactating cows in summer and lactating and dry cows in winter. J Dairy Sci 85 2813-2822.

Sartori R, Sartor-Bergfelt R, Mertens SA, Guenther JN, Parrish JJ \& Wiltbank MC 2002b Fertilization and early embryonic development in heifers and lactating cows in summer and lactating and dry cows in winter. J Dairy Sci 85 2803-2812.

Souza AH, Ayres H, Ferreira RM \& Wiltbank MC 2008 A new presynchronization system (Double-Ovsynch) increases fertility at first postpartum timed $\mathrm{Al}$ in lactating dairy cows. Theriogenology 70 208-215.

Souza AH, Gümen A, Silva EP, Cunha AP, Guenther JN, Peto CM, Caraviello DZ \& Wiltbank MC 2007 Supplementation with estradiol-17beta before the last gonadotropin-releasing hormone injection of the Ovsynch protocol in lactating dairy cows. J Dairy Sci 90 4623-4634.

Souza AH, Silva EP, Cunha AP, Gümen A, Ayres H, Brusveen DJ, Guenther JN \& Wiltbank MC 2011 Ultrasonographic evaluation of endometrial thickness near timed $\mathrm{Al}$ as a predictor of fertility in high-producing dairy cows. Theriogenology 75 722-733.

Souza EDF, Sala RV, Ortolan MDDV, Azrak AJ, Maio JRG, Teixeira AA, Bastos MR, Sales JNS \& Baruselli PS 2013. Effects of exogenous progesterone on luteal function of high production dairy cows. In: XXVII Annual Meeting of the Brazilian Embryo Technology Society (SBTE) 2013, Praia do Forte. Proceedings: Anim Reprod 10(3) 446 Abstract.

Spencer TE \& Gray CA 2006 Sheep uterine gland knockout (UGKO) model. Methods Mol Med 121 85-94. 
Stevenson JS, Tiffany SM \& Lucy MC 2004 Use of estradiol cypionate as a substitute for $\mathrm{GnRH}$ in protocols for synchronizing ovulation in dairy cattle. J Dairy Sci $\mathbf{8 7}$ 3298-3305.

Sá Filho MF, Crespilho AM, Santos JE, Perry GA \& Baruselli PS 2010 Ovarian follicle diameter at timed insemination and estrous response influence likelihood of ovulation and pregnancy after estrous synchronization with progesterone or progestin-based protocols in suckled Bos indicus cows. Anim Reprod Sci 120 23-30.

Sá Filho MF, Santos JE, Ferreira RM, Sales JN \& Baruselli PS 2011 Importance of estrus on pregnancy per insemination in suckled Bos indicus cows submitted to estradiol/ progesterone-based timed insemination protocols. Theriogenology 76 455-463.

Vasconcelos JL, Sangsritavong S, Tsai SJ \& Wiltbank MC 2003 Acute reduction in serum progesterone concentrations after feed intake in dairy cows. Theriogenology $\mathbf{6 0}$ 795-807.

Vasconcelos JL, Sartori R, Oliveira HN, Guenther JG \& Wiltbank MC 2001 Reduction in size of the ovulatory follicle reduces subsequent luteal size and pregnancy rate. Theriogenology 56 307-314.

Vasconcelos JL, Sá Filho OG, Justolin PL, Morelli P, Aragon FL, Veras MB \& Soriano S 2011 Effects of postbreeding gonadotropin treatments on conception rates of lactating dairy cows subjected to timed artificial insemination or embryo transfer in a tropical environment. J Dairy Sci 94 223-234.

Wehrman ME, Roberson MS, Cupp AS, Kojima FN, Stumpf TT, Werth LA, Wolfe MW, Kittok RJ \& Kinder JE 1993 Increasing exogenous progesterone during synchronization of estrus decreases endogenous 17 beta-estradiol and increases conception in cows. Biol Reprod 49 214-220.

Wiltbank MC \& Pursley JR 2014 The cow as an induced ovulator: timed Al after synchronization of ovulation. Theriogenology 81 170-185.

Wiltbank MC, Sartori R, Herlihy MM, Vasconcelos JL, Nascimento AB, Souza AH, Ayres H, Cunha AP, Keskin A, Guenther JN \& Gumen A 2011 Managing the dominant follicle in lactating dairy cows. Theriogenology 76 1568-1582.

Wiltbank MC, Souza AH, Giordano JO, Nascimento AB, Vasconcelos JM, Pereira MHC, Fricke PM, Surjus RS, Zinsly FCS \& Carvalho PD 2012 Positive and negative effects of progesterone during timed $\mathrm{Al}$ protocols in lactating dairy cattle. Anim Reprod 9 231-241.

Wolfenson D, Inbar G, Roth Z, Kaim M, Bloch A \& Braw-Tal R 2004 Follicular dynamics and concentrations of steroids and gonadotropins in lactating cows and nulliparous heifers. Theriogenology 62 1042-1055. 